\title{
Economic Management of Late Blight (Phytophthora infestans L.) of Potato in Eastern Tarai of Nepal
}

\author{
Prem CP Chaurasia \\ Regional Agriculture Research Station-NARC, Tarahara
}

\begin{abstract}
Field experiments were carried out at Regional Agriculture Research Station, Tarahara in three consecutive years (1997-2000) during winter season to know the economic sprays of different fungicides to manage late blight disease of potato. Late blight susceptible cultivar of potato Kufri Sindhuri was used for the experiment. Krinoxyl gold (metalaxyl 8\% and mancozeb 64\%) at the rate of $1.5 \mathrm{~g} / \mathrm{l}$, Dithane M- 45 (mancozeb 75\%) @ 0.3\% and Bordeaux mixture @ $10 \mathrm{~g}$ copper sulfate and $10 \mathrm{~g}$ lime $/ \mathrm{l}$ of water and their different combinations were tested in randomized complete block design with three replications. Terminal disease severity was the highest (7.9) on 0-9 scale disease rating in unsprayed check and it was significantly higher than those of other fungicides sprays. Plots with three sprays of Dithane M- 45 @ 0.3\% recorded the lowest (2.4) terminal disease severity. Disease development was the fastest in the unsprayed plot compared to all other treatments. Similarly apparent infection rate was the highest in unsprayed treatment. Area Under the Disease Progress Curve was also the highest in unsprayed plot and it was significantly higher than those of other treatments. Tuber yield was the lowest ( $3.93 \mathrm{~kg} / 4.5$ $\mathrm{m}^{2}$ plot in unsprayed and the highest $(6.08 \mathrm{~kg})$, in the plot receiving four sprays of Dithane M-45 @ $0.3 \%$ and this was at par with the tuber yield of plots receiving two and three sprays of Dithane M-45. Benefit cost ratio was the highest (1.54) in case of two sprays of Dithane M-45 @ $0.3 \%$ at 10 days intervals. All others fungicide spays were uneconomical under Eastern Tarai condition.
\end{abstract}

Key words: Eastern Tarai, economic spray, Dithane M-45, late blight management, potato

\section{INTRODUCTION}

Potato (Solanum tuberosum) is an important stable food in high hills and is the best vegetable crop in mid hill and Terai (plain area) of Nepal (ABPSD 2000). Late blight of potato, caused by Phytophthora infestans (Mont) de Barry is the most important disease of potato worldwide (Hardy et al 1995). It is the most destructive disease of potato in India (Singh 1996). The disease causes heavy losses in susceptible cultivar of potato annually in mid and high hills of Nepal but its occurrence in Tarai is restricted to every third year when weather is conducive to the disease development. Many fungicides, contact and systemic are available to manage the disease and farmers are using them many times to protect their crops. There is a tendency of development of resistant fungal races against use of systemic fungicides (Singh 1996). Josepovits and Dobrevalszky (1985) reported that the use of fungicides with different modes of action is the best strategy to delay build up of resistance. Farmers of this area are not aware of economic number of sprays of different fungicides. Singh (1996) reported that one spray of Ridomil MZ @ $0.25 \%$ plus six sprays of Dithane M-45 @ $0.2 \%$ gave the highest cost benefit ratio in northwestern hills of India. Farmers in this area spray four to five times Dithane M- 45 to manage the disease. This study was undertaken to determine economic number of sprays of different fungicides to manage late blight disease of potato in the Eastern Tarai condition of Nepal. 


\section{MATERIALS AND METHODS}

Field experiments were conducted in three years (1997/98-1999/2000) during the winter season at Regional Agriculture Research Station (RARS), Tarahara, situated at 100 masl in the Tarai of Eastern Development Region of Nepal. In all the experimental seasons trials were planted during the first week of Nov. Kufri Sinduri was used as susceptible check test variety of potato. The trial was carried out in complete randomized block design with three replications and individual plot size of $3-\times 3-\mathrm{m}$. The trial was fertilized at the rate of 100:100:60 kg NPK/ha. Net plot was 1.8- $\times 2.5-\mathrm{m}$. Three fungicides Krinoxyl gold @1.5 g/l (metalaxyl 8\% and mancozeb 64\%), Dithane M-45 @ 3 g/l (mancozeb 75\%) and Bordeaux mixture $10 \mathrm{~g}$ of copper sulfate and $10 \mathrm{~g}$ of lime/l of water were used in different combinations. All fungicides were used when first symptoms of late blight disease was observed (first week of January). Fungicides were sprayed at 10 days interval. Disease severity was scored using CIP 1-9 scale Hardy et al 1995). Terminal disease score (observed first week of February), tuber yield per net plot and Area Under the Disease Progress Curve (AUDPC) were analyzed using MSTAT-C computer program. Apparent infection rate (Vander Plank 1963), which is given by formula !/t $t_{2}-\mathrm{t}_{1 \mathrm{x}} \operatorname{loge}$ $\mathrm{x}_{2}\left(1-\mathrm{x}_{1}\right) / \mathrm{x}_{1}\left(1-\mathrm{x}_{2}\right)$ where $\mathrm{t}_{2}$ and $\mathrm{t}_{1}$ are date of disease observations and $\mathrm{x}_{1}$ and $\mathrm{x}_{2}$ are percent disease score divided by hundred and Area under the Disease Progress Curve (Shaner and Finney 1997) given by $\left(\mathrm{t}_{1}+\mathrm{t}_{2}\right) \mathrm{x}\left(\mathrm{x}_{1}+\mathrm{x}_{2}\right) / 2$ where $\mathrm{t}_{1}$ and $\mathrm{t}_{2}$ are same as in apparent rate of infection and $\mathrm{x}_{1}$ and $\mathrm{x}_{2}$ are disease score value of that date, were calculated. Benefit cost ratio of number of sprays of each treatment was calculated by taking the ratio of total values in term of money of additional tuber yield of a treatment over unsprayed check and total cost of spray of fungicide involved in that treatment.

\section{RESULTS AND DISCUSSION}

\section{Effect of fungicides on disease severity and disease development curves}

All the treatments were significantly superior to unsprayed check in reducing terminal disease severity. Plot receiving three sprays of Dithane M-45 @ 0.3\% was able to record the lowest disease severity, 2.4 on CIP scale compared to unsprayed check, 7.9 (Table 1). It was superior to all other fungicides spray treatments in reducing terminal disease severity. Two sprays of Dithane M-45 @ 0.3\% had mean terminal disease severity of 3.2 on CIP scale and this was at par with two sprays of Krinoxyl gold @ 1.5 $\mathrm{g} / \mathrm{l}$, four sprays of Krinoxyl gold, one spray of Krinoxyl gold plus three sprays of Dithane M-45, two sprays of Krinoxyl gold plus two sprays of Dithane M-45, one spray of Krinoxyl gold plus three sprays of Bordeaux mixture, two sprays of Krinoxyl gold plus two sprays of Bordeaux mixture and three sprays of Bordeaux mixture. Three sprays of Krinoxyl gold, four sprays of Dithane M-45, three sprays of Krinoxyl gold plus one spray of Dithane M-45 and four sprays of Bordeaux mixture were superior to all other treatments in reducing mean terminal disease severity (Table 1).

Table 1. Effect of fungicide sprays on disease severity, AUDPC, apparent infection rate (r), tuber yield and benefit cost ratio (1997/98-99/2000)

\begin{tabular}{|c|c|c|c|c|c|}
\hline $\mathrm{TN}$ & Description & $\begin{array}{r}\text { Terminal } \\
\text { disease score }\end{array}$ & JDPC & $\mathrm{r}$ & $\begin{array}{l}\text { Tuber } \\
\text { yield, } t / h a\end{array}$ \\
\hline 1 & Control (water spray only) & 7.9 & 123.9 & 0.275 & 8.52 \\
\hline 2 & Krinoxyl gold @ 1.5 g/lit - 2 sprays & 3.0 & 50.9 & 0.065 & 12.52 \\
\hline 3 & Krinoxyl gold @ 1.5 g/lit - 3 spray & 2.9 & 51.2 & 0.081 & 11.58 \\
\hline 4 & Krinoxyl gold@1.5 g/lit - 4 sprays & 3.0 & 53.6 & 0.064 & 10.54 \\
\hline 5 & Dithane M-45@3g/lit-2 spray & 3.2 & 58.7 & 0.072 & 12.98 \\
\hline 6 & Dithane M-45@3 g/lit - 3 sprays & 2.4 & 53.3 & 0.042 & 12.75 \\
\hline 7 & Dithane M-45@3 g/lit - 4 sprays & 2.9 & 54.2 & 0.086 & 13.50 \\
\hline 8 & Krinoxyl gold 1 spray plus Dithane M-45 - 3 sprays & 3.4 & 55.2 & 0.072 & 11.60 \\
\hline 9 & Krinoxyl gold 2sprays plus Dithane M-45 - 2 sprays & 3.0 & 52.1 & 0.081 & 9.50 \\
\hline
\end{tabular}




\begin{tabular}{llrrrr}
\hline TN & Description & $\begin{array}{c}\text { Terminal } \\
\text { disease score }\end{array}$ & & $\mathrm{r}$ & $\begin{array}{r}\text { Tuber } \\
\text { yield, t/ha }\end{array}$ \\
& & 2.9 & 58.3 & 0.055 & 10.54 \\
10 & Krinoxyl gold 3 sprays plus Dithane M-45 - 1 spray & 3.0 & 61.4 & 0.055 & 10.42 \\
11 & Krinoxylgold-1 spray+ Bordeauxmixture - 3 sprays & 3.0 & 52.5 & 0.098 & 12.25 \\
12 & Krinoxyl gold 2 spray + Bordeux mixture - 2 sprays & 3.0 & 57.4 & 0.068 & 10.98 \\
13 & Krinoxyl gold3sprays + Bordeaux mixture - 1 spray & 3.9 & 73.7 & 0.098 & 12.0 \\
14 & Boredeaux mixture - 2 sprays & 3.3 & 62.7 & 0.071 & 10.51 \\
15 & Bordeaux mixture - 3 sprays & 2.9 & 51.9 & 0.046 & 11.85 \\
16 & Bordeaux mixture - 4 sprays & $* *$ & $* *$ & & $* *$ \\
& F test & 25.8 & 21.12 & & 23.85 \\
CV, & 0.29 & 4.27 & & 0.41 \\
SED & & & & \\
\hline
\end{tabular}

Late blight disease was developed faster in unsprayed check compared to all other treatments. It was very fast after $3^{\text {rd }}$ week of January and reached a maximum at first week of Feb. All the treatments except unsprayed check had similar type of disease development curves (Figure 1). This indicated that all the fungicides under test were equally effective in managing late blight disease of potato under Tarai condition.

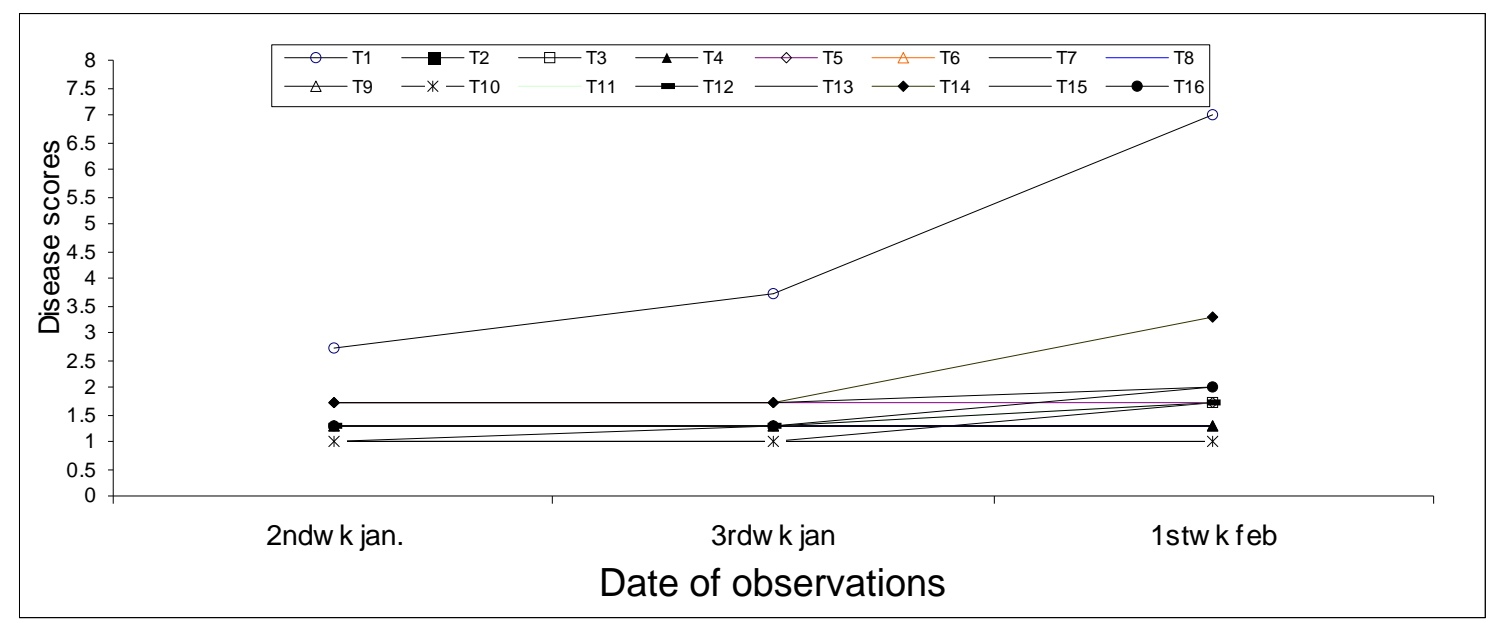

Figure 1. Disease development curves of different fungicide sprays.

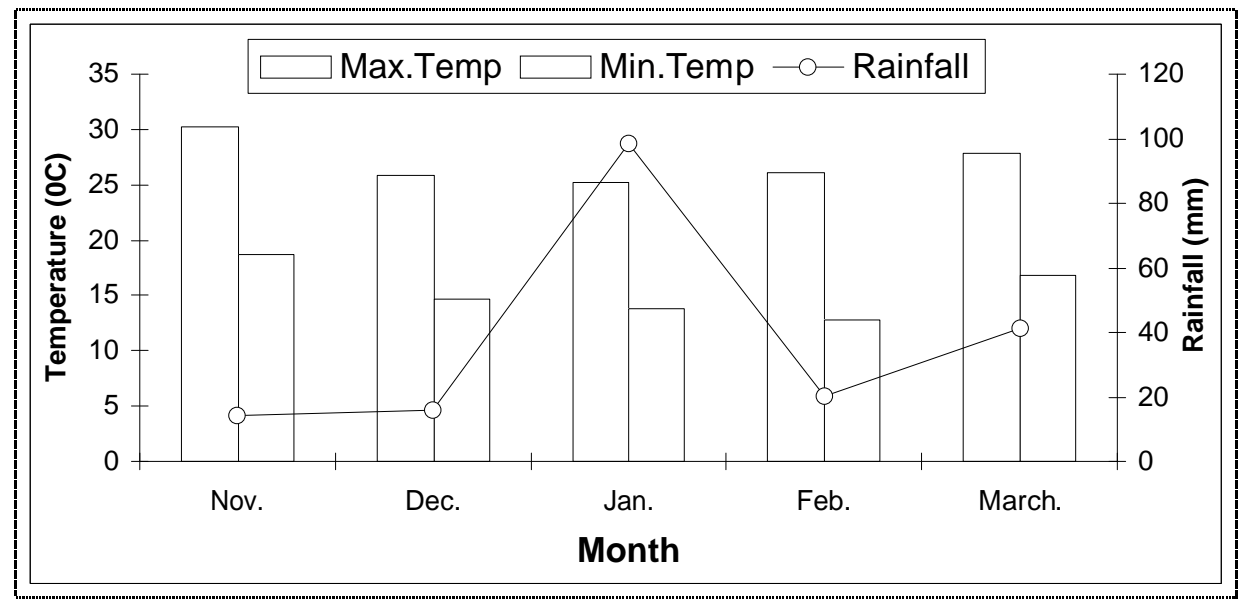

Figure 2. Mean weather parameter of three years during potato growth period. 
Prevailing weather during potato growth period influences relative humidity inside the crop canopy and hence favor the disease spread and development in the crop. The canopy of crop growth was medium and that helped in quicker drying of relative humidity and dew presence on leaf surface in the plot. This had considerably reduced the number of sprays of different combinations of fungicides in reducing terminal disease severity. Rainfall received in January had enhanced the disease development. In Jan and $\mathrm{Feb}$ minimum temperature was around $15^{\circ} \mathrm{C}$ and maximum temperature $25^{\circ} \mathrm{C}$ (Figure 2). Disease development and number of protective fungicide sprays in potato depend on canopy of the crop growth and weather conditions of crop growth period.

Table 2. Benefit cost ratio analysis

\begin{tabular}{lrrrrr}
\hline TN & $\begin{array}{r}\text { Tuber yield, } \\
\text { kg/plot }\end{array}$ & $\begin{array}{r}\text { Additional tuber } \\
\text { yield, kg/plot }\end{array}$ & $\begin{array}{r}\text { Value of additional } \\
\text { tuber yield, Rs }\end{array}$ & $\begin{array}{r}\text { Additional cost of } \\
\text { spray/plot, Rs }\end{array}$ & Benefit cost ratio \\
\hline T1 & 3.833 & 0.0 & 0.0 & 0.0 & - \\
T2 & 5.633 & 1.8 & 9.0 & 13.23 & 0.68 \\
T3 & 5.211 & 1.378 & 6.09 & 19.92 & 0.35 \\
T4 & 4.744 & 0.911 & 4.56 & 26.56 & 0.17 \\
T5 & 5.844 & 2.011 & 10.06 & 6.52 & 1.54 \\
T6 & 5.756 & 1.923 & 9.62 & 9.78 & 0.98 \\
T7 & 6.078 & 2.245 & 11.23 & 13.04 & 0.86 \\
T8 & 5.256 & 1.423 & 7.12 & 16.42 & 0.43 \\
T9 & 4.278 & 0.445 & 2.23 & 19.8 & 0.11 \\
T10 & 4.744 & 0.911 & 4.56 & 23.58 & 0.19 \\
T11 & 4.689 & 0.856 & 4.28 & 23.59 & 0.18 \\
T12 & 5.511 & 1.678 & 8.39 & 24.58 & 0.34 \\
T13 & 4.944 & 1.111 & 5.56 & 25.57 & 0.22 \\
T14 & 5.4 & 1.576 & 7.84 & 11.3 & 0.69 \\
T15 & 4.733 & 0.9 & 4.5 & 22.6 & 0.27 \\
T16 & 5.333 & 1.5 & 7.5 & 16.95 & 0.33 \\
\hline
\end{tabular}

Potato, Rs 5.00/kg. Dithane M-45, Rs 420/kg. Krinoxyl Gold, Rs 232/100g. Copper sulfate, Rs 170/kg. Lime, Rs 25/kg. Labor charge, Rs 60/8 hrs.

\section{Effect of fungicides on apparent infection rate and AUDPC}

Three sprays of Dithane M-45 had the lowest apparent infection rate followed by four sprays of Bordeaux mixture, three sprays of Krinoxyl gold plus one spray of Dithane M-45 and one spray of Krinoxyl gold plus three sprays of Bordeaux mixture. Two sprays of Krinoxyl gold, four sprays of Krinoxyl gold and three sprays of Krinoxyl gold plus one spray of Bordeaux mixture had similar apparent infection rates (Table 1). However, their AUDPC differ significantly. The highest apparent infection rate was in the case of unsprayed check (0.275). Two sprays of Dithane M-45, one spray of Krinoxyl gold plus three sprays of Dithane M-45 and three sprays of Bordeaux mixture had similar apparent infection rates but their AUDPC differed significantly among themselves (Table 1).

Area Under the Disease Progress Curve (AUDPC) was the highest in case of unsprayed check and all other treatments had significantly lower AUDPC compared to unsprayed check (Table 1). AUDPC of the plots receiving two sprays of Krinoxyl gold, three sprays of Krinoxyl gold, four spray of Krinoxyl gold, three sprays of Dithane M-45, four sprays of Dithane M-45, one spray of Krinoxyl gold plus three sprays of Dithane M-45, two sprays of Krinoxyl gold plus two sprays of Dithane M-45, two sprays of Krinoxyl gold plus two sprays of Bordeaux mixture and four sprays of Bordeaux mixture were statistically at par. AUDPC of plot receiving two sprays of Dithane M-45 was significantly higher to all above mentioned treatments but significantly lower to the AUDPC of plot receiving two and three sprays of Bordeaux mixture Krinoxyl gold one spray plus three sprays of Dithane M-45 and unsprayed 
check. This indicates that the fungicides under test were equally good in managing the late blight disease of potato.

\section{Effect of fungicides on tuber yield}

Unsprayed plot yielded significantly the lowest (8.52 t/ha) compared to all other treatments ranging the tuber yield of 9.5 to $13.5 \mathrm{t} / \mathrm{ha}$ (Table-1). However tuber yields of plots receiving four spray of Dithane M-45 was the highest but at par with plots receiving two sprays of Krinoxyl gold, two sprays of Dithane M- 45 and three sprays of Dithane M- 45. All other treatments were inferior in respect to tuber yield to above three mentioned treatments. This indicates that Dithane M-45 had effect on increasing tuber yield in addition to lowering the late blight disease severity. Results of this experiment showed that use of Dithane M-45 for the management of late blight of potato was beneficial for the potato growers of Eastern Tarai.

\section{Benefit cost ratio of sprays of fungicides}

The benefit cost ratio of different combinations of fungicide sprays indicated that two sprays of Dithane M-45 @ 0.3\% gave the highest ratio (1.54), followed by three (0.98) and four sprays (0.86) of Dithane M-45. Singh (1996) reported that one spray of Ridomil MZ plus six sprays of Dithane M-45 gave the highest cost benefit ratio in north-western hill of India. The weather condition of north-western hill of India during potato growing period is different than that of Eastern Tarai. All other fungicide sprays tested in this study proved uneconomical in managing late blight disease of potato. However efficacy of fungicide treatment combinations in controlling disease were at par (Table 2) Even three and four sprays of Dithane M-45 were uneconomical in managing late blight disease of potato. Late blight severity did not reach at even 8 score. This is mainly because of medium crop canopy and that might lead to relatively slow disease development in all the years of experimentation.

Under the condition of Tarahara two sprays of Dithane M-45 @ 0.3\% will be the most economical fungicide spray schedule for the management of late blight disease of potato in the first week of Nov planted potato in most years of potato cultivation. However, in certain year, three sprays of Dithane M45 may be needed to manage late blight disease of potato. All other fungicides available in the market are effective in managing the late blight disease of potato but would not be of cost effective in managing late blight disease of potato in Eastern Tarai condition of Nepal.

\section{ACKNOWLEDGEMENT}

The author is very much thankful to DK Chaudhary, Horticulture Research Program and DP Bhattarai of RARS, Tarahara for their help in conducting the experiment.

\section{REFERENCES}

ABPSD. 2000. Statistical information on Nepalese agriculture 2000/2001 (2057/58). Agriculture Business Promotion and Statistics Division-MOAC, HMG/N, Singhdurbar-Kathmandu.

Hardy B, B Trognitz and G Forbes. 1995. Late blight breeding at CIP. CIP Circular (Lima-Peru) 21:2-5.

Josepovits G and A Dobrevalszky. 1985. A novel mathematical approach to the prevention of fungicide resistance. Pesticide Sci. 16:17-22.

Shaner G and RE Finney. 1997. The effect of nitrogen fertilization on the expression of slow mildewing resistance in Knox wheat. Phytopathology 67:1051-1056.

Singh D. 1996. Fungicidal spray schedule for economical management of potato late blight in North-western hills of India. Indian J. Mycol. Pl. Pathol. 1.2:252-255.

Vander Plank JE. 1963. Plant disease epidemics and control. Academic Press, New York and London. 349pp. 